\title{
TU/e EmonONEN

\section{0-to-40 Gb/s demultiplexing using a single SOA assisted by an optical filter}

\section{Citation for published version (APA):}

Tangdiongga, E., Liu, Y., Waardt, de, H., Khoe, G. D., \& Dorren, H. J. S. (2006). 320-to-40 Gb/s demultiplexing using a single SOA assisted by an optical filter. IEEE Photonics Technology Letters, 18(8), 908-910. https://doi.org/10.1109/LPT.2006.872332

DOI:

10.1109/LPT.2006.872332

Document status and date:

Published: 01/01/2006

\section{Document Version:}

Publisher's PDF, also known as Version of Record (includes final page, issue and volume numbers)

\section{Please check the document version of this publication:}

- A submitted manuscript is the version of the article upon submission and before peer-review. There can be important differences between the submitted version and the official published version of record. People interested in the research are advised to contact the author for the final version of the publication, or visit the $\mathrm{DOI}$ to the publisher's website.

- The final author version and the galley proof are versions of the publication after peer review.

- The final published version features the final layout of the paper including the volume, issue and page numbers.

Link to publication

\section{General rights}

Copyright and moral rights for the publications made accessible in the public portal are retained by the authors and/or other copyright owners and it is a condition of accessing publications that users recognise and abide by the legal requirements associated with these rights.

- Users may download and print one copy of any publication from the public portal for the purpose of private study or research.

- You may not further distribute the material or use it for any profit-making activity or commercial gain

- You may freely distribute the URL identifying the publication in the public portal.

If the publication is distributed under the terms of Article 25fa of the Dutch Copyright Act, indicated by the "Taverne" license above, please follow below link for the End User Agreement:

www.tue.nl/taverne

Take down policy

If you believe that this document breaches copyright please contact us at:

openaccess@tue.nl

providing details and we will investigate your claim. 


\title{
320-to-40-Gb/s Demultiplexing Using a Single SOA Assisted by an Optical Filter
}

\author{
E. Tangdiongga, Y. Liu, Member, IEEE, H. de Waardt, Member, IEEE, G. D. Khoe, Fellow, IEEE, and
} H. J. S. Dorren, Member, IEEE

\begin{abstract}
We demonstrate excellent all-optical demultiplexing of $40-\mathrm{Gb} / \mathrm{s}$ base-rate channels out of $160-$ and $320-\mathrm{Gb} / \mathrm{s}$ single polarization optical time-division-multiplexed data streams. The demultiplexer utilizes a semiconductor optical amplifier and an optical filter placed at the amplifier output. The center wavelength of the filter is blue-shifted from the wavelength of the clock signal, so that ultrafast chirp dynamics can be employed for optical switching. Error-free demultiplexing was achieved at very low optical switch powers: $3.5 \mathrm{~mW}(160-\mathrm{Gb} / \mathrm{s} \mathrm{data}), 6.3 \mathrm{~mW}(320-\mathrm{Gb} / \mathrm{s}$ data), and $0.09 \mathrm{~mW}$ (40-GHz clock). The proposed demultiplexer has a simple structure and allows monolithic integration.
\end{abstract}

Index Terms-Optical time-division multiplexed (OTDM) demultiplexing, semiconductor nonlinear optics, semiconductor optical amplifier (SOA).

\section{INTRODUCTION}

$\mathbf{O}$ PTICAL demultiplexers, which extract a signal channel at the base rate of a time-multiplexed high-bit-rate data stream, form a key functionality in optical time-division-multiplexed (OTDM) networks. Optical demultiplexers with ultrashort switching gates can be realized by utilizing fiber nonlinearities [1] and semiconductor devices [2]-[4]. Fiber-based optical switches can provide an ultrabroad conversion band and ultrahigh-speed operation but at the expense of high optical powers and performance instability. Semiconductor optical amplifier (SOA)-based demultiplexing techniques are particularly attractive because they feature small size, high stability, low switching energy, and high integration potential.

A number of SOA-based demultiplexers have been proposed in the literature. Four-wave mixing in an SOA can successfully demultiplex 160-40 Gb/s [2], but this scheme suffers from low efficiency, preventing it to operate for higher data rates. All-optical switches using SOAs in an optical interferometer can realize $160-10 \mathrm{~Gb} / \mathrm{s}$ [3], however, the maximum attainable base rates are severely limited by the SOA slow recovery time. Electrooptical switches have been employed to demultiplex $40-\mathrm{Gb} / \mathrm{s}$ base channels from a $160-\mathrm{Gb} / \mathrm{s}$ data stream [4], but a shorter switching time is difficult to achieve.

In this letter, we present a high-performance all-optical demultiplexer employing a single SOA. We show that the concept is able to demultiplex $160 / 320$ to $40 \mathrm{~Gb} / \mathrm{s}$ with very low

Manuscript received October 28, 2005; revised January 11, 2006. This work was supported by The Netherlands Technology Foundation STW Project EET6491, by the Innovational Research Incentives Scheme Program, by the European Commission funded program IST-LASAGNE (FP6-507509), and by the NRC Photonics Grant.

The authors are with the COBRA Research Institute, Eindhoven University of Technology, Electro-Optical Communication Systems, NL-5600 MB Eindhoven, The Netherlands (e-mail: E.Tangdiongga@tue.nl).

Digital Object Identifier 10.1109/LPT.2006.872332

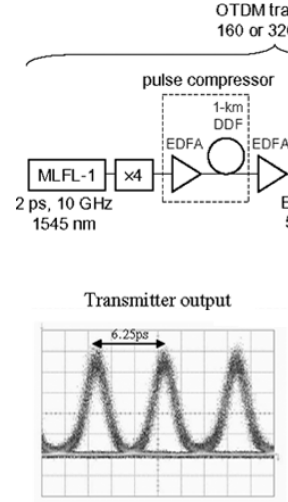

(b)

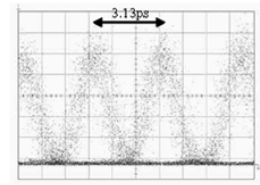

(e) r
Tom transmitter

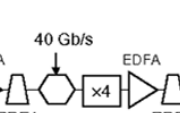

$\mathrm{BPF} 1$
$5 \mathrm{~nm}$

(a)

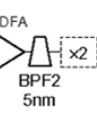

$\begin{array}{ll}\text { BPF3 } & \text { BPF4 } \\ 1.5 \mathrm{~nm} & 0.5 \mathrm{~nm}\end{array}$

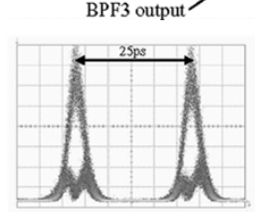

(c)

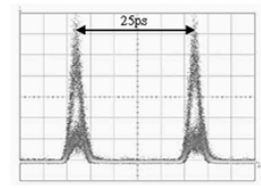

(f)

(d)

(g)
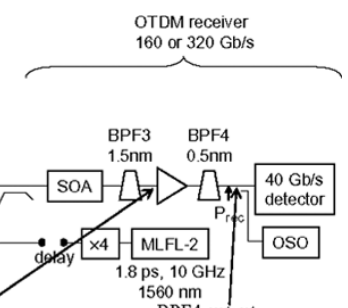

BPF4 output
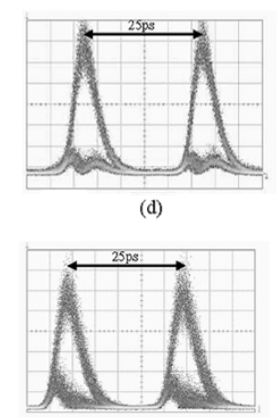

Fig. 1. Experimental setup for the all-optical demultiplexer: (a) schematic diagram; (b)-(g) eye diagrams at various positions in the setup. The eye diagrams are obtained from a 700-GHz optical sampling oscilloscope (OSO). BPF: bandpass filter. $x$ : pulse interleaver.

switching powers. The SOA has an initial gain recovery time of $>90 \mathrm{ps}$, which based on its length of $800 \mu \mathrm{m}$ can only demultiplex error-free OTDM signals to base rates of $<40 \mathrm{~Gb} / \mathrm{s}$ using conventional concepts. An essential part in our approach is that we employ an optical bandpass filter which is slightly detuned from the data signal (see [5] and references therein) to utilize ultrafast chirp dynamics in the SOA [6], thus shortening the recovery time of the demultiplexer. This fast recovery results in higher attainable base rates, i.e., $40 \mathrm{~Gb} / \mathrm{s}$ and above. A similar approach has been successfully demonstrated for $160-\mathrm{Gb} / \mathrm{s}$ wavelength conversion [6]. This approach has a simple configuration and allows photonic integration.

\section{EXPERIMENTAL SETUP AND RESULTS}

The experimental setup as shown in Fig. 1 consists of an OTDM transmitter and an OTDM receiver in a back-to-back configuration. The setup was constructed with commercially available components. For the transmitter, a 2-ps $10-\mathrm{GHz}$ optical clock signal $\left(\lambda_{s}=1545 \mathrm{~nm}\right)$ that outputs from an actively mode-locked fiber laser (MLFL- 1$)$ is optically quadrupled $(\times 4)$ to $40 \mathrm{GHz}$ and is subsequently modulated to form a $40-\mathrm{Gb} / \mathrm{s}$ base rate of $2^{7}-1$ return-to-zero pseudorandom binary sequence (PRBS). This $40-\mathrm{Gb} / \mathrm{s}$ data signal is further time-multiplexed to 160 or $320 \mathrm{~Gb} / \mathrm{s}$ by using passive pulse interleavers $(\times 2, \times 4)$. 


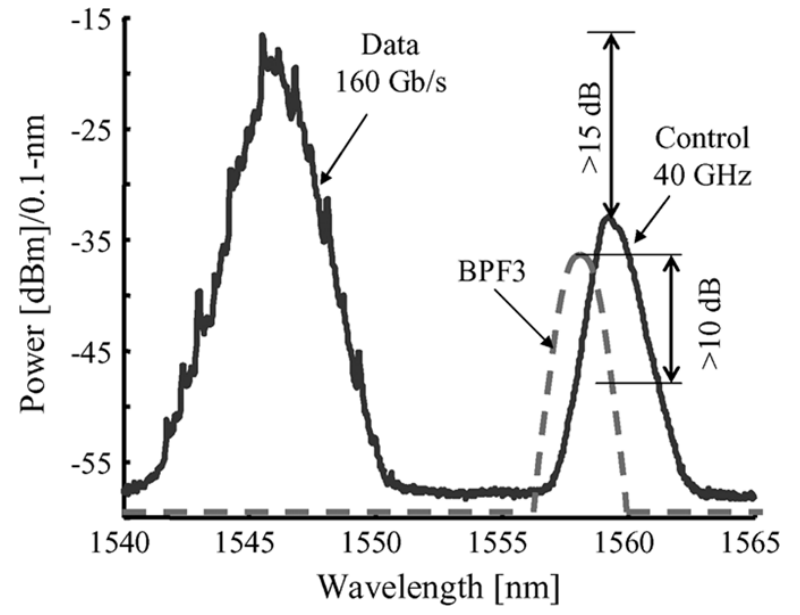

Fig. 2. Spectral location of the optical filter BPF3 relative to the data and control pulse. BPF3 is blue-shifted $1 \mathrm{~nm}$ from the control wavelength.

For the 320-Gb/s OTDM transmitter, the 40-GHz clock pulses are compressed down to 0.8 ps by using a $1-\mathrm{km}$ dispersion-decreasing fiber (DDF). The 160/320-Gb/s data signal is combined with a clock signal that consists of a 40-GHz 1.8-ps pulse train. This signal is at $\lambda_{c}=1560 \mathrm{~nm}$ and is also generated by optically quadrupling $(\times 4)$ the $10-\mathrm{GHz}$ pulses that output from MLFL-2. The data and control pulses are coupled into the OTDM receiver via a $3-\mathrm{dB}$ coupler. The receiver comprises the proposed demultiplexer and a 40-Gb/s photodetector. As shown in Fig. 1(a), our demultiplexer is made out of an SOA and a 1.5-nm optical filter (BPF3) for creating an ultrashort switching gate. To improve the optical signal-to-noise ratio (OSNR) of the demultiplexed signal, we used an erbium-doped fiber amplifier (EDFA) and a $0.5-\mathrm{nm}$ optical filter (BPF4). The SOA is a product from Kamelian that was designed as a preamplifier. The $800-\mu \mathrm{m}$ SOA has the following properties: the bias current is $250 \mathrm{~mA}$, the small signal gain $23 \mathrm{~dB}$, the saturation output power $12 \mathrm{dBm}$, and the noise figure $6.5 \mathrm{~dB}$. The SOA linewidth enhancement factor is estimated to be 3-7 [6]. The average optical powers injected to the SOA for optimum demultiplexing are $3.5 \mathrm{~mW}$ (160-Gb/s data signal), $6.3 \mathrm{~mW}$ (320-Gb/s data signal), and $0.09 \mathrm{~mW}$ (40-GHz control signal).

The working principle of this concept has been expeditiously explained in [5] and [6] for the case of wavelength conversion. The continuous wave probe light in [5] and [6] is replaced by the $40-\mathrm{GHz}$ control pulses in our demultiplexer. The principle can be summarized as follows. In the SOA, the injected data signal at $\lambda_{s}$ acts as pump and modulates the SOA gain. As a result, the control pulse at $\lambda_{c}$ is affected via cross-gain modulation, causing an inverted demultiplexing operation. Moreover, the injected data signal also modulates the refractive index of the SOA, resulting in a chirped control signal. The leading edge of the control pulse is red-shifted, whereas the trailing edge is blue-shifted. As a consequence, the spectrum of the control pulse is broadened. The center passband of BPF3 at the SOA output is slightly blue-shifted from the control wavelength in order to compensate the slow gain recovery, leading to a narrow and inverted switching window with steep slopes. The spectral location of BPF3 relative to the data and control pulse is depicted in Fig. 2 for the case of demultiplexing $160 \mathrm{~Gb} / \mathrm{s}$. The BPF3 slope at $\lambda_{c}$ is approximately $-0.002 / \mathrm{GHz}$. It can be observed in Fig. 2 that the central wavelength of BPF3 is located

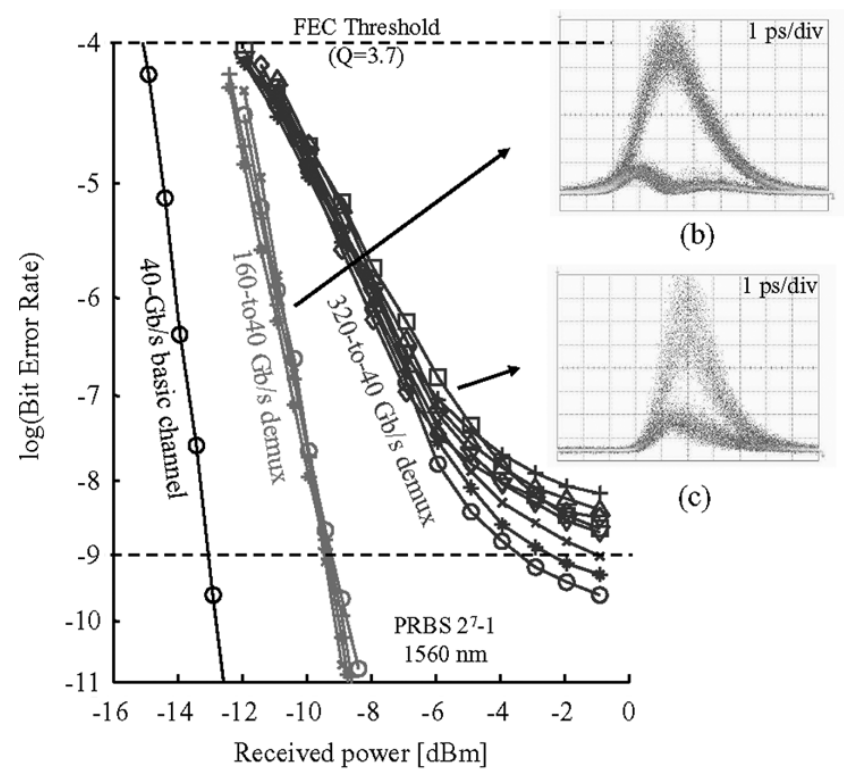

(a)

Fig. 3. Demultiplexing performance: (a) BER values and eye patterns of demultiplexing (b) 160-to-40 Gb/s and (c) 320-to-40 Gb/s. FEC: forward error correction. $Q$ : Gaussian parameter. For $Q=3.7$, the error probability is $10^{-4}$.

approximately $1 \mathrm{~nm}$ from the central wavelength of the control pulses. This setting introduces approximately $10-\mathrm{dB}$ additional loss in the control signal. Therefore, an EDFA is placed at the output of BPF3 to enhance the signal OSNR above the desired detection threshold.

Fig. 1(b) and (e) shows the eye diagram of 160 and $320 \mathrm{~Gb} / \mathrm{s}$, respectively, as observed by using an optical sampling oscilloscope with an optical measurement bandwidth up to $700 \mathrm{GHz}$. Fig. 1(c) and (f) depicts the demultiplexed $40 \mathrm{~Gb} / \mathrm{s}$ as taken directly after BPF3 for $160-$ and $320-\mathrm{Gb} / \mathrm{s}$ input signal, respectively. For the 160-40-Gb/s demultiplexing, the eyes are clearly open with a residual pulse fragment around the zero level. This eye performance is much better than the eyes of the $320-40-\mathrm{Gb} / \mathrm{s}$ demultiplexing. This residual pulse is caused by the fact that the control pulse [1.8-ps full-width at half-maximum (FWHM)] is much wider than the data pulse (0.8-ps FWHM). Since the data pulse for $320 \mathrm{~Gb} / \mathrm{s}$ is shortened by the long DDF, the data pulse drifts continuously from the control pulse, making difficult to perform an accurate eye-diagram analysis. This slow drift is largely caused by the small variation in the ambient thermal condition of the DDF. The clear opening of the eye diagrams in Fig. 1(c) and (f) demonstrates a significant improvement of the recovery time to less than $3 \mathrm{ps}$. To increase the signal contrast ratio, we employed an EDFA followed by a narrow filter BPF4, i.e., stretching the pulse within the bit period. The output of the 0.5-nm BPF4 is displayed in Fig. 1(d) and (g). The pulse becomes wider but the eye opening improves considerably, relaxing the setting of the detection threshold. The base-rate signal is then coupled into the $40-\mathrm{Gb} / \mathrm{s}$ detector and a bit-error-rate (BER) tester. The tester used the clock signal of the PRBS generator. Fig. 3(a) shows BER values of the $40-\mathrm{Gb} / \mathrm{s}$ base-rate signal from 160 and $320 \mathrm{~Gb} / \mathrm{s}$. For comparison purposes, we also present in Fig. 3(a) BER values of the $40-\mathrm{Gb} / \mathrm{s}$ basic channel before the multiplexing stage. First, we detail the case of demultiplexing 160-40 Gb/s. It can be observed from Fig. 3(a) and (b) that all four 40-Gb/s tributaries of $160 \mathrm{~Gb} / \mathrm{s}$ 


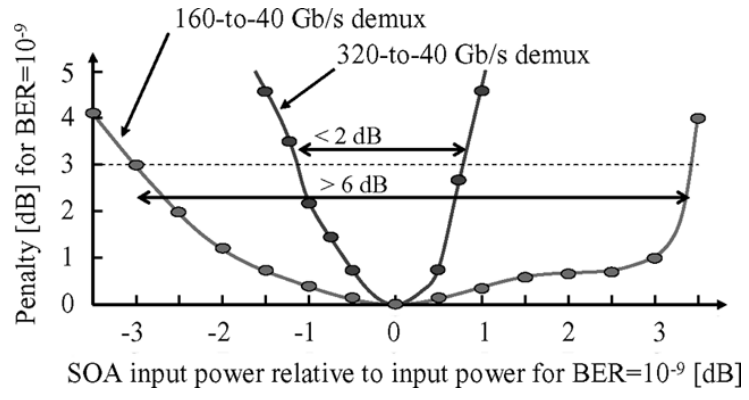

Fig. 4. SOA input power dynamic range of the demultiplexer. The penalties indicate the allowable input power fluctuation of the SOA for $B E R=10^{-9}$

show an identical performance and that the penalty for BER $=10^{-9}$ is less than $3.5 \mathrm{~dB}$ when compared to the reference $40-\mathrm{Gb} / \mathrm{s}$ basic channel. This penalty can be considered small since it also includes penalties of the multiplexing stage. Moreover, it is visible that no error floor is observed, which indicates excellent performance of the demultiplexer. Next, a pulse compressor is employed to achieve shorter pulses for multiplexing to $320 \mathrm{~Gb} / \mathrm{s}$. A demultiplexed 40-Gb/s eye diagram is presented in Fig. 3(c). Fig. 3(a) shows that demultiplexing 320-40 Gb/s using this concept gives varying results. The eight $40-\mathrm{Gb} / \mathrm{s}$ tributaries show error floors, but all below a BER of $10^{-8}$. The BER values are significantly better than the forward-error-correction threshold for $\mathrm{BER}=10^{-12}$. We believe that the error floors are caused by the wide control pulse, the drift of the data pulse, and the high noise level of the data pulse. The input OSNR of the demultiplexer on average is less than $17 \mathrm{~dB}$, inducing less chirp in the SOA and, therefore, less contrast ratio of the demultiplexing gate than the case of $160 \mathrm{~Gb} / \mathrm{s}$. Moreover, the absence of synchronization between the data and the control pulses made it extremely difficult to keep the demultiplexing gate constant. Better signal contrast ratios are possible if the control pulse is compressed to the same width or even narrower than the data pulse. Chirp induced by the data pulse will then affect the entire width of the control pulse, and not only a part of it as in the present case.

Plots in Fig. 3 are obtained for constant data and control powers. This is in practice not always the case because the data signal arriving at receivers fluctuates in power due to various transmission impairments. Fig. 4 shows the penalties as a function of power deviations of the data signal at the input of the SOA. The plots in Fig. 4 were made as follows. The net effect of chirp depends on the total input power to the SOA for a certain pulsewidth. For each curve, we initially set the data signal power at the SOA input to correspond to BER of $10^{-9}$. Then, we varied the data signal power to worsen the receiver sensitivity, which is followed by tuning the power of the control pulse to return the system performance back to BER of $10^{-9}$. We performed this input dynamic range measurement for 160 and $320 \mathrm{~Gb} / \mathrm{s}$. For low input powers, the performance is asymptotically bounded by low OSNR values. For high input powers, the performance deteriorates due to the too strong gain saturation, causing wider demultiplexing gate. For a penalty of $3 \mathrm{~dB}$ as the maximum allowable deterioration, the demultiplexer can cope with the fluctuation of the data power as much as $6 \mathrm{~dB}$ for $160 \mathrm{~Gb} / \mathrm{s}$ and $2 \mathrm{~dB}$ for $320 \mathrm{~Gb} / \mathrm{s}$. The small dynamic range of the 320-to-40-Gb/s demultiplexer is due to the low input OSNR and the instability of the demultiplexing gate.

\section{DISCUSSION AND CONCLUSION}

The SOA in the setup initially has $>90$-ps recovery time. For demultiplexing based on conventional cross-gain/phase modulation, this $800-\mu \mathrm{m}$ SOA only allows operating bit rates of less than $40 \mathrm{~Gb} / \mathrm{s}$. Our approach achieved $<3$-ps recovery time, enabling us to process $320 \mathrm{~Gb} / \mathrm{s}$. This data rate is higher than the rates reported in [2]-[4]. The crucial point here is to utilize BPF3 to select the blue-shifted sideband of the chirped control pulses. The center of BPF3 is detuned by $1 \mathrm{~nm}$ to the blue side of the control wavelength. This detuning is a compromise between the maximum contrast ratio and the minimum power loss of the switching gate. In the setup, an additional EDFA was used to compensate for losses affected by the detuned filter. The use of an EDFA is not essential here since optical gain can be delivered by an SOA. The proposed demultiplexer does not restrict itself to a specific device. However, a better demux performance can be obtained if an SOA is used that produces more chirp.

In conclusion, we have demonstrated a new concept of time-domain demultiplexing that is based on the filtered chirp using only one SOA. The demultiplexer has been successfully tested for 160-to-40-Gb/s demultiplexing with small penalties. A reasonably good performance is also obtained for 320-to-40-Gb/s demultiplexing. Although all eight $40-\mathrm{Gb} / \mathrm{s}$ tributaries show relatively low error floors, a considerable improvement in BER values is believed to possibly be realized if the performance of the data, control pulse, and their synchronization are enhanced. Finally, we wish to underline that the proposed demultiplexing concept has a simple configuration, requires low switching powers, and allows photonic integration.

\section{ACKNOWLEDGMENT}

The authors would like to acknowledge Siemens Research in Munich for making mode-locked lasers available.

\section{REFERENCES}

[1] S. Watanabe, R. Okabe, F. Futami, R. Hainberger, C. SchmidtLanghorst, C. Schubert, and H. G. Weber, "Novel fiber Kerr-switch with parametric gain: Demonstration of optical demultiplexing and sampling up to $640 \mathrm{~Gb} / \mathrm{s}$," in Proc. ECOC 2004, Stockholm, Sweden, Postdeadline paper Th3.1.6.

[2] S. L. Jansen, M. Heid, S. Spälter, E. Meissner, C.-J. Weiske, A. Schöplin, G. D. Khoe, and H. de Waardt, "Demultiplexing $160 \mathrm{~Gb} / \mathrm{s}$ OTDM signal to $40 \mathrm{~Gb} / \mathrm{s}$ by FWM in SOA," Electron. Lett., vol. 38, pp. 978-980, Aug. 2002.

[3] C. Schubert, C. Schmidt, S. Ferber, R. Ludwig, and H. G. Weber, "Errorfree all-optical add-drop multiplexing at $160 \mathrm{~Gb} / \mathrm{s}$," Electron. Lett., vol. 39, pp. 1075-1076, Jul. 2003.

[4] H. F. Chou, J. E. Bowers, and D. J. Blumenthal, "Compact 160-Gb/s add-drop multiplexing with a 40-Gb/s base-rate," in Proc. OFC 2004, Los Angeles, CA, Postdeadline paper PDP28.

[5] H.-Y. Yu, D. Mahgerefteh, P. S. Cho, and J. Goldhar, "Optimization of the frequency response of a semiconductor optical amplifier wavelength converter using fiber Bragg grating," J. Lightw. Technol., vol. 17, no. 2, pp. 308-315, Feb. 1999.

[6] Y. Liu, E. Tangdiongga, Z. Li, S. Zhang, H. de Waardt, G. D. Khoe, and H. J. S. Dorren, "Error-free all-optical wavelength conversion at 160 $\mathrm{Gb} / \mathrm{s}$ using a semiconductor optical amplifier and an optical bandpass filter," J. Lightw. Technol., vol. 24, no. 1, pp. 230-236, Jan. 2006. 